\title{
Sustainable Intervention Plans for Igbo Cultural Region of Nigeria
}

\author{
Bartho Ekweruo ${ }^{1}$ and Nnezi Uduma-Olugu ${ }^{2}$ \\ 1. Department of Horticulture and Landscape Architecture, Imo State Polytechnic, Umuagwo 464119, Nigeria \\ 2. Department of Architecture, University of Lagos, Lagos 100001, Nigeria
}

\begin{abstract}
The Igbos are one of the major tribes of Nigeria. Over the years, their distinct way of living have further accentuated their culture. The paper discusses the Igbo cultural landscape region which comprises of rural autonomous communities made up of clusters of kindred and villages. In spite of the existence of the townships serving as trade, political and administrative centers for more than one century, the rate of urbanization has been very slow thereby affecting the development of the communities physically, economically and socially at astonishing rates consuming farmlands and traditional community boundaries. This paper is aimed at creating awareness on the unique regional growth pattern in Igbo land heavily dependent on cultural and natural heritages for purpose of determining adaptable regional planning strategies for such vibrant cultural region. It has examined the key issues and suggested a way forward to a more sustainable development of the region.
\end{abstract}

Key words: Igbo cultural landscape, sustainable interventions, erosion, ecological consequences, urban growth patterns, Nigeria.

\section{Introduction}

The Igbo cultural landscape region comprises of rural autonomous communities made up of clusters of kindred and villages until the colonial period when townships were established about $64 \mathrm{~km}$ interval by the colonial masters for ease of administration. In spite of the existence of the townships serving as trade, political and administrative centers for more than one century, the rate of urbanization is very slow. Communities have developed physically, economically and socially at astonishing rates consuming farmlands and traditional community boundaries. Such unmanaged growth obviously has serious social and ecological consequences. There is need for appropriate regional landscape planning strategies for sustainable growth in the cultural area.

The objectives include:

(1) Defining the territory and determining the regional characteristics of Igbo cultural landscape;

(2) Discussing the Igbo traditional region in cultural

Corresponding author: Nnezi Uduma-Olugu, M.Sc., research fields: landscape, tourism, architecture and urban design. E-mail: nnezi.udumaolugu@gmail.com. terms to understand the meaning and existence of traditional elements and values of social and economic importance;

(3) Determining the nature and extent of formal intervention through regional planning;

(4) Determining the consequence of the unmanaged growth;

(5) Suggesting sustainable intervention plans adaptable in the region.

\section{Methodology}

The authors adopted a methodology considered very reliable by making reference to the levels of studies carried out by one of them since 1981—when he was a graduate student at the University of Pennsylvania, Philadelphia USA [1]. They had also monitored the trend of development in the region through frequent travels to all parts since 1985. As Igbo indigenes raised in Igbo region, residing in the city in Igbo land and commuting to their native communities in response to the various traditional calls for kindred, village and community services, meeting, voluntary and mandatory contribution for 
community projects, special church services, ceremonies, traditional festivals and one having served as President General of his autonomous community their experience as active participators in the traditional way of life in Igbo cultural region should be considered wholesome and very relevant. They also applied the phenomenological approach using the cultural landscape concept for understanding the regional characteristics of Igbo land, as shown in Figs. 1 and 2.

\section{Definition of Key Terms}

Some key terms such as landscape, culture, control mechanism, suburbanization, megacoms as applied in this paper are defined in the context which they are used:

(1) Landscape: landscape is the totality of what you see feel, and experience physically outdoors at any particular time and place in the natural or cultural state [2];

(2) Natural landscape: Natural landscape result when there is no interruption by man through any land use or the interruption is so minimal that the natural status is intact, e.g., wilderness, mountains, rocky hills etc.;

(3) Cultural landscape: This results when nature is interrupted by man through the introduction or replacement of any part of the natural environment with desired landscape such as gardens, campuses, market places, roads etc.;

(4) Culture: Within the context of the numerous definitions may be seen as the interplay of attitudes, thoughts, values aspiration and technology of a specific society manifested in physical or non-physical forms in the landscape through various representative symbols and expressions such as markets, village square, palaces rituals and dance, their distribution and inter connectivity in time and space as ideals of the society [3]. Culture is indestructible unless the society is completely displaced but undergoes changes when those changes are reflected in thoughts. Changes or Interventions in any cultural landscape are effectively functional in the context of the existing culture;

(5) Suburbanization: This is a term used to described spontaneous or planned growth of a rural

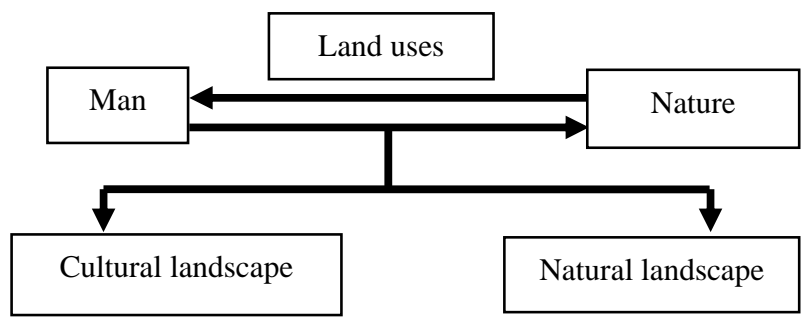

Fig. 1 Interaction of man and nature through land uses.

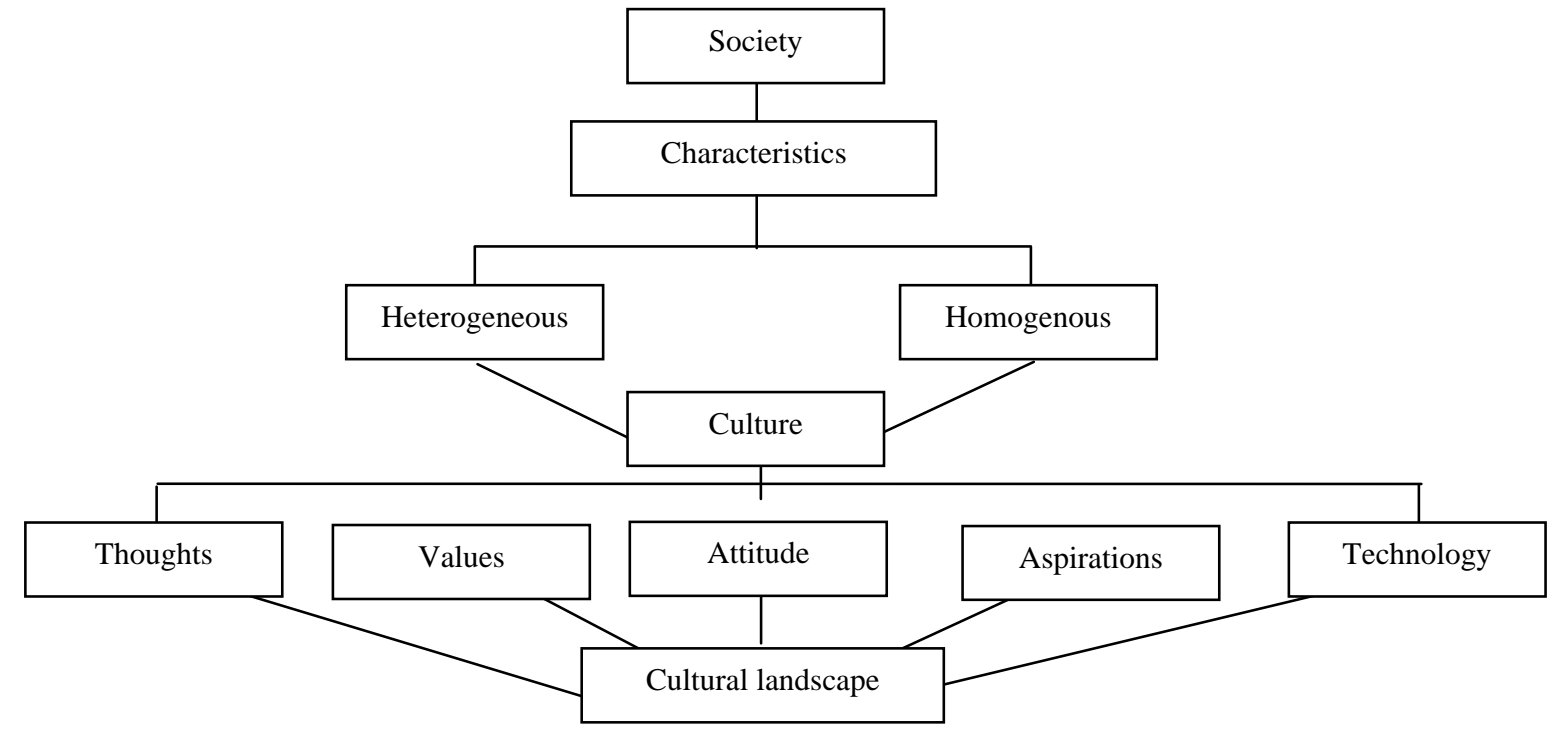

Fig. 2 Cultural landscape. 
community through community development effort or by designation of the place as regional administrative center and or by over-spill population from a nearby city in which case the community serves as a bedroom community until it attains suburban status;

(6) Control mechanism: This term refers to the structure or structures that keep any society, operation or system in continuous existence and may include traditional Town Unions, NGOs (Non Governmental Organizations), government agencies, market authorities, youth organization etc. [1];

(7) Megacom: This term is coined out of mega community to express huge scale or super size traditional societies of multiple communities with population of more than 50,000 sharing common ancestral origin and identity. Such megacom in Igbo land includes Mbaise, Ikeduru, Ogwa, Nnewi South, Umuaka, Amaigbo, Ideato North, Ekwulobia area etc..

\section{Regional Characteristics of Igbo Cultural Landscape}

\subsection{Physical Characteristics}

The Igbo region lies about latitude $5^{\circ}$ north of the equator within the humid tropical rainforest zone.

The small Igbo territory covers only about 41,538 $\mathrm{km}^{2}$ (Fig. 3) and is characterized by Mosaic landscape comprising scarp-lands, portion of the Niger Delta, the palm belt and the western edge of the Cross River Basin [4]. The expansive scarp-lands with such landforms as hills, plateaus, valleys, escarpments and ridges are located in the northern part of the region while numerous creeks, streams, wetlands, rivers and other water bodies are in the southern part thus reducing developable area by about $30 \%$. The modest hills and valleys, numerous water shades and rivers and streams, as well forests give the landscape a human sense of state and combined to create the framework for the settlement of the numerous clustered communities.

\subsection{Demographic Characteristics}

According to 1963 census, the population of the former East Central State which forms the core of Igboland was 6,223,831 people and urban population was only 752,884 with 13 townships classified as urban [5].

With only about $12.1 \%$ of population living in urban areas, it is clear that the Ibo region is traditionally not urbanized. Today the population has grown to about $20,000,000$ on net developable land area of about $28,078 \mathrm{~km}^{2}$ making the population density about 700 per square kilometer. Urban areas have risen to about 50 suggesting that 37 communities have grown up organically to be classified as township or urban. At the same time, villages have metamorphosed into autonomous communities while many autonomous communities transformed into suburban areas. Many communities coalesced spontaneously to form megacoms (Mega communities).

It is on the limited land area that we have five states, five state capitals, three large commercial cities (Onitsha, Aba, Nnewi), five other urban areas or townships, 10 megacoms, numerous suburban areas, about 2,250 autonomous communities and 125 local government headquarters all connected with federal highways, regional roads, rural roads and community roads.

\subsection{Cultural Characteristics}

Ibos have settled permanently in the same territory since about 2000 B.C. [6]. They have established in the region outstanding cultural and historical landmarks and remarkable natural elements that distinguished them from other races in Nigeria particularly and the world in general. The Ibo civilization established wealth of knowledge in terms of costumes, dance, language, arts and crafts, technology, religion, politics, food, education, aspiration, agriculture, architecture, entrepreneurship, settlement pattern, market system, medicine, metallurgy, 


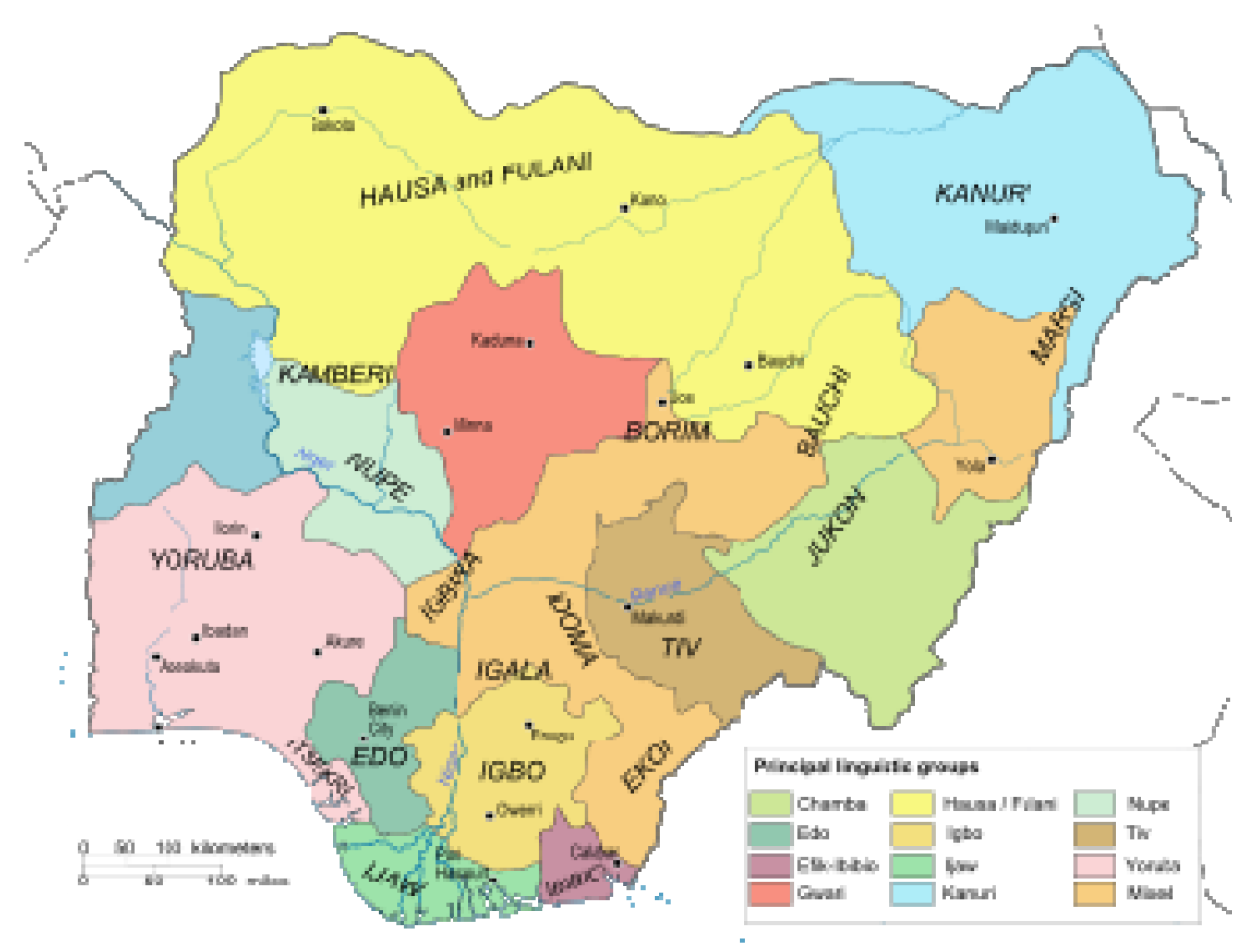

Fig. 3 Igbo region in geopolitical setting.

meteorology, science, metaphysics and ethno-botany and all of these are reflected in the cultural landscape of the region [7].

Peace, development and stability in extended relationship was ensured through complex interplay of inter/intra community marriages, matrilineal (maternal) connections and effective market system that ensures regular contact for exchange of goods information and message [8]. The cluster pattern of settlement was adopted as an adaptation to gross scarcity of land and for effective resource conservation.

Ibos are egalitarian in nature. High sense of aspiration, entrepreneurship, strong tie to native home and hard working attitude are the key factors that have sustained continuous growth in the region. Ibos are found in most parts of the world but family identity and allegiance to the native community is maintained through sending parts of the proceeds home to contribute for the sustenance of the home based family members and community development. Traditionally Ibos are not urbanized unlike the Yoruba, Hausa and the Westerners. Urban residence is a temporary abode as he strives hard to make money in the city to satisfy the "Igbo Dream", i.e., to build a comfortable house in the native home which is his final resting place [9].

\subsection{Economic Characteristics}

Trading is the traditional occupation of the Ibos who inherited scarce land that has over the centuries been impoverished because of continuous cultivation and exposure of soil to lengthy and heavy rainfall (annual average of 2,500-3,000 mm). The local economy in the region is sustained through the traditional market system comprising hierarchy of daily, four-day and eight-day markets. The eight-day markets are inter community markets serving multiple communities within their sphere of influence and are the pivots for development and potential regional growth centers [10]. As market days vary alternatively traders are always on the move to patronize big markets within their reach hence the highly mobile nature of the Ibos with the markets acting as magnetic forces recycling goods, information and money. 
Farming has been the traditional complimentary occupation of the Ibos on which trading heavily depends. There is hardly any household that does not raise livestock - native hen, sheep and goats generally. Arable crops, spices, vegetables and fruits are produced through intercropping methods in distant and at close-to-home farms. The rural economy is reinforced by the fact that most of the agriculture products reach the markets in multiple forms (e.g., cassava marketed as tuber, or processed to be marketed as tapioca in fresh or dry form, fresh or cooked fufu, tapioca cake, local salad, (local delicacy) flour, stem etc.. Much of this takes place in the village square, along with other cultural activities.

Palm trees provide palm fruits that sustain numerous cottage palm processing industries, while also provide palm kernels, palm leaves, brooms, baskets, palm wine, rafters and purlins for building, palm kernel oil, fish and crab traps and decomposed by product that is recycled in gardens, hence the multi-level labor and trading opportunities for children, women and men [11].

\subsection{Land Use Heritage}

Today there are about 2,500 autonomous communities in the limited land area forming clusters of human settlements comprising compounds (Fig. 4), kindreds (Fig. 5) and villages.

Each community is sustained by at least two primary schools, one secondary school, commercial schools, skill acquisition workshops, church parishes (Catholic and Protestant), many Pentecostal churches, hospitals or health centers, maternity homes, community banks, market places and numerous trading activities. The communities are connected through intra and intercommunity routes.

Hence the complex network of routes connect the communities (Figs. 6 and 7), village centers and markets serving as nodes to ensure continuous flow of movement for trading activities and exchange of information in the region. There lies the magic for the continuous rapid development in Igbo cultural landscape region with communities constituting themselves into growth points.

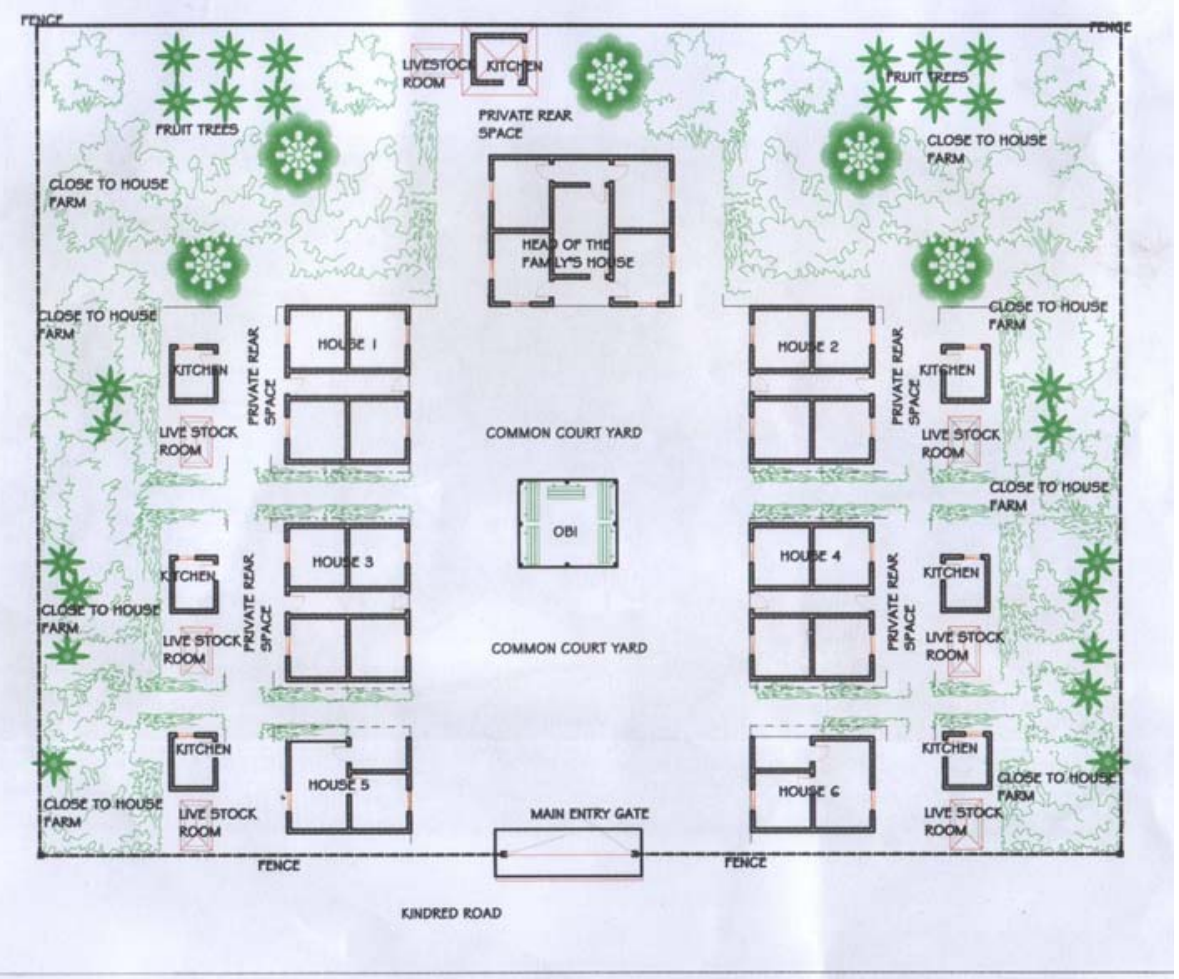

Fig. 4 Compound setting. 


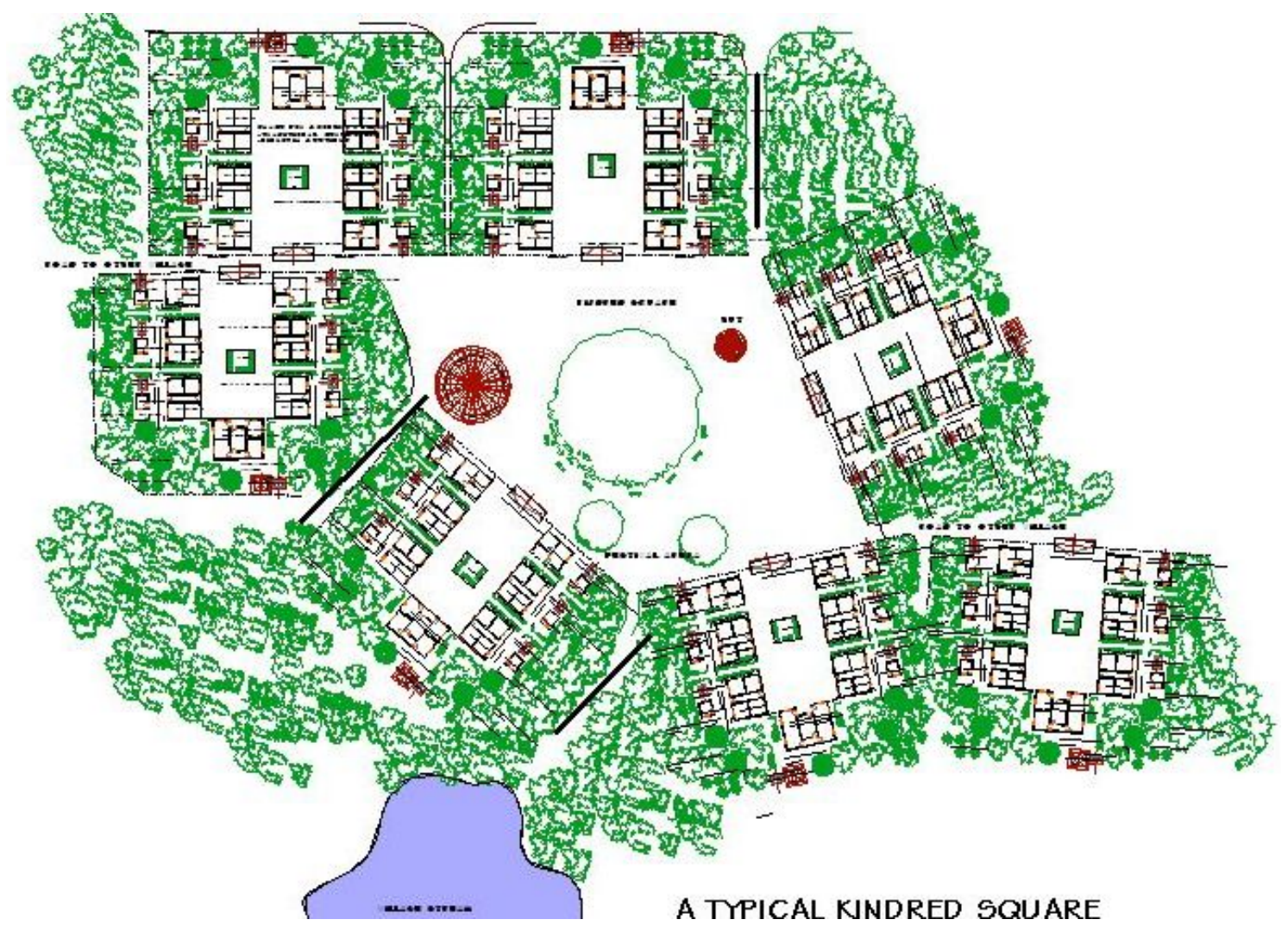

Fig. 5 Kindred/village setting.

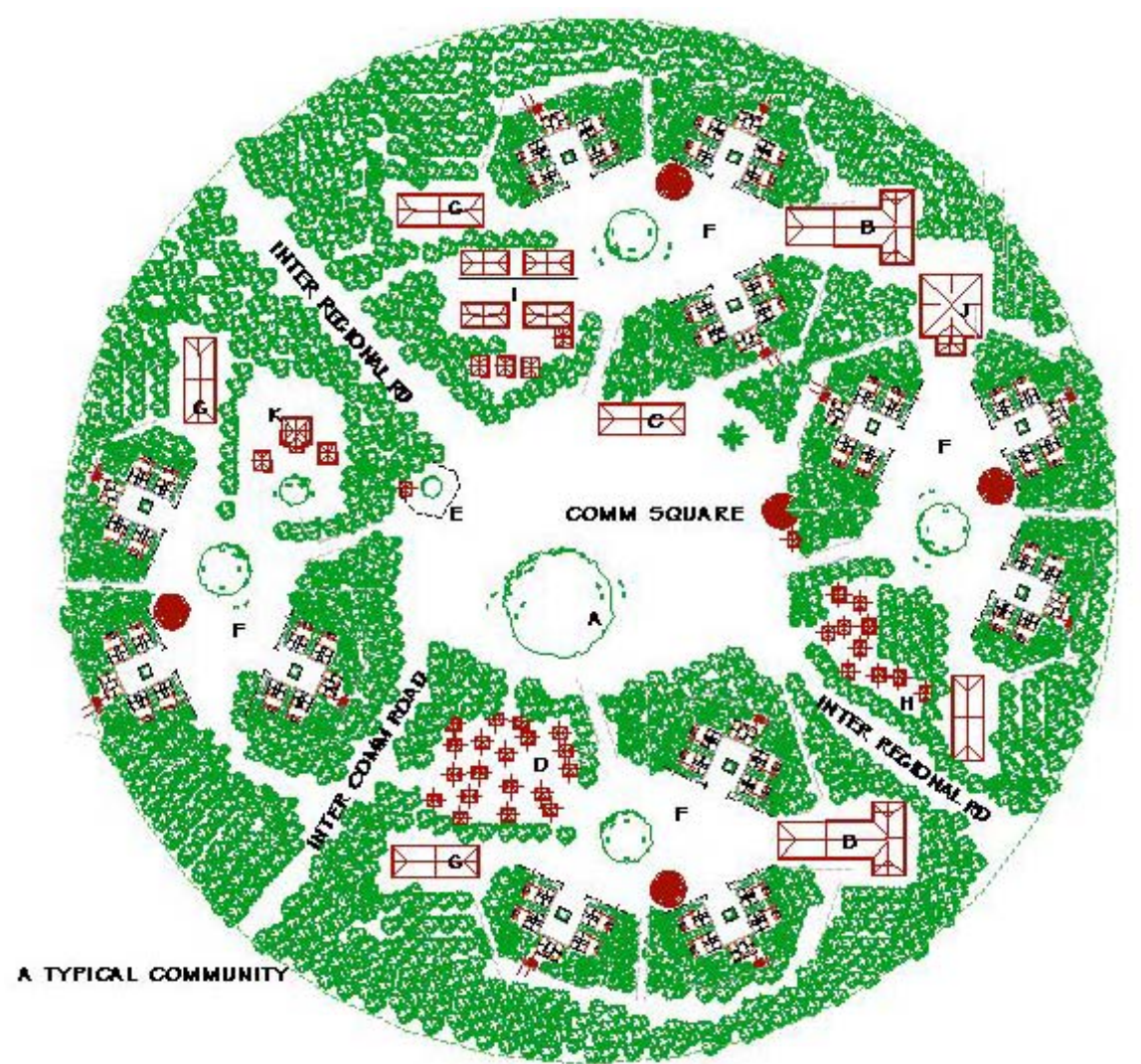

a - COMM SQUARE

B - COMN CHURCHE

C - CONM HALL

D - B DAY MARKET

E - COWH DEITY

F - VILLAGE SQUARE

G - VILLAGE HALL

H - VILLA DAY WARKET

I - SCHOOL

J - CONM CLINIC

K - kINGS pAlace

Fig. 6 A typical village/community square. 


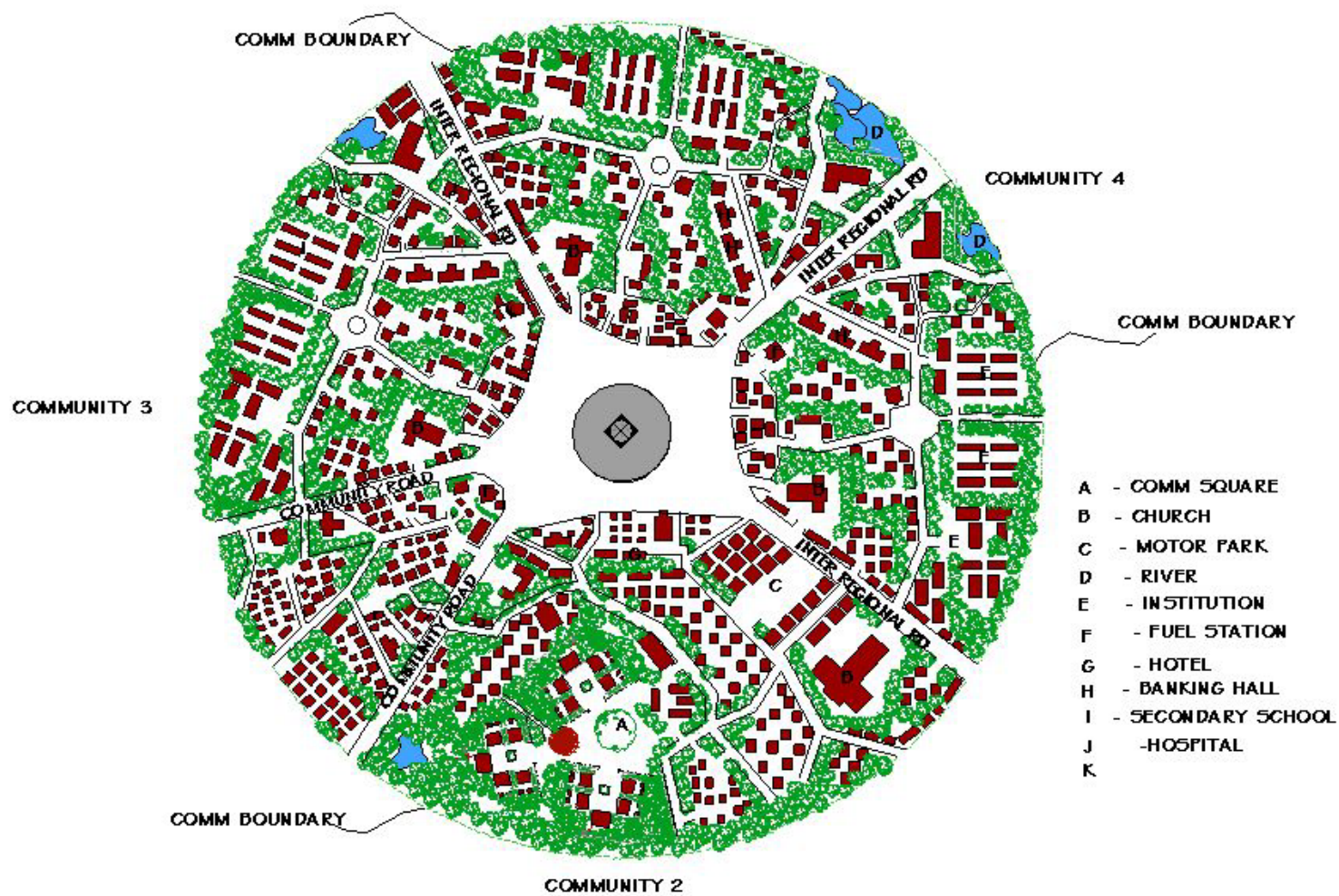

Fig. 7 Suburbanization of communities, unplanned development eat up farmlands, forest resources and escalate gully erosion.

\subsection{Igbo Spirit and the Process of Growth}

At the end of the civil war in 1970, more young males and females out of poverty moved to urban areas to learn trading, venture in skill acquisition in areas of tailoring, carpentry, building, machines and automobile repairs paint production, food processing block moulding, tool fabrication etc., through apprenticeship. With inherited work attitudes, sense of aspiration and entrepreneurship many successfully graduated and established their business, Trainees and apprentices who graduated within specified period were established by their masters to become trainers and traders. Hence the wheel of progress was established across the region. Young men who took advantage of the open door policies of the far eastern countries traveled and established contacts that brought volumes of goods, small and medium scaled industries into the region. The rural village and communities naturally positioned as satellite settlements to nearby cities and urban areas provide cheap land and labor for the industries and with regular electricity and borehole water provide peaceful places for the Chinese, Koreans and others to establish the industries.

An Ibo adage says "there is strength in population". The continuous growth in population was also traditionally provided for in the case of youth training or education through apprenticeship agreement in trading and acquisition of skills. The strong rural economy is therefore sustained by the steady flow of fund in the region through mandatory and voluntary contributions, rural cottage industries, strong market system, many rural workers and students, churches, service trades, banks, high volume of transportation business, local government headquarters and the enterprising traders, artisans and technocrats who compete traditionally in fund raising, building country homes, factories, schools, civic centers hospitals and other life support facilities.

All these therefore explain the comparatively slow rate of development in cities and relatively high rate 
of rural development in the region. Hence a simultaneous regional growth pattern in which the rural areas aggressively are competing with the urban areas and the resultant effect is that the rural areas are wearing urban characters.

\subsection{Control Mechanism}

The control mechanism in Ibo rural communities comprises the Traditional Rulers and the town unions. The traditional rulers are the custodians of culture and tradition and vested with power of ensuring security. The town unions organize political, social and development activities in the respective autonomous communities and hence constitute the fourth tier government. Unfortunately, the town unions cannot execute planning and development control because of lack of professional competence and fund to sustain trained physical planners.

Building activities are not formally regulated or controlled as many villages and communities are beyond the control of established planning authorities. Shortages of trained planning officers restrict extension services to untrained planning attendants easily enticed with money. There is no rural based or community based physical planning that is sound enough to have broad based control on the aggressive development in rural areas in comparison with level of control in urban area under planning authorities.

\section{Issues and Consequences}

The issues and consequence of uncontrolled or unmanaged growth in Igbo rural landscape are obvious.

The traditional cluster method of housing in compounds which ensured economy in land management, common use of space and conservation of resources was replaced with the anti-social western style houses hence acute shortage of land and destruction of farmlands.

Buildings are erected without regards for existing natural order hence flood plains are occupied, drainage courses are blocked, air ways blocked and aquifer recharge areas are blocked with ecological consequences (Figs. 8 and 9).

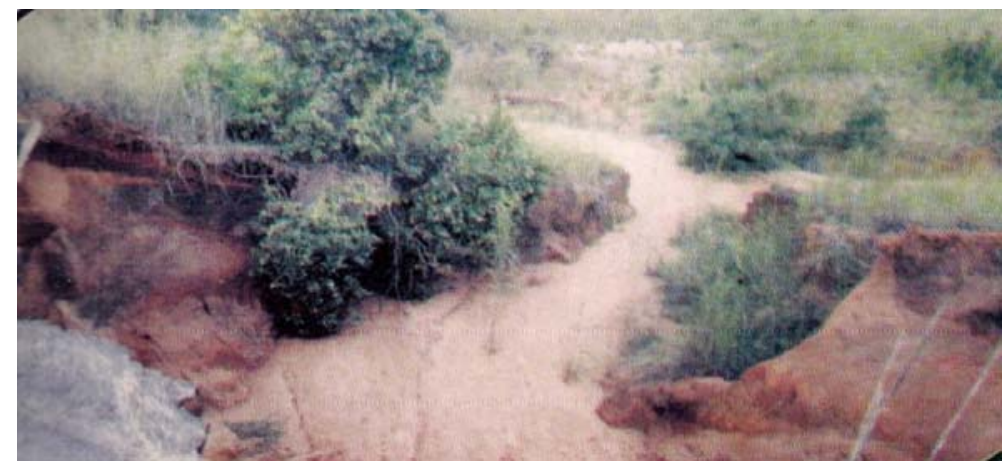

Fig. 8 Gully erosion in every part of the region.

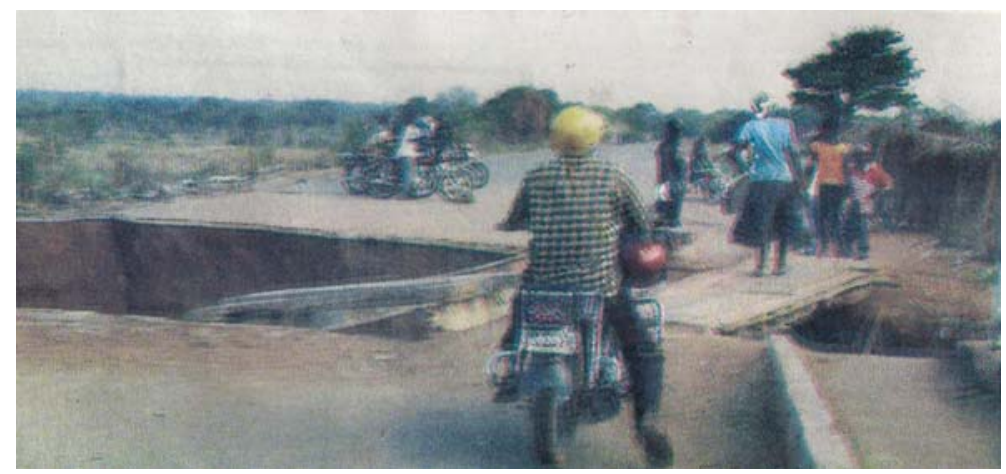

Fig. 9 Continuous menace of gully erosion in every part of the region. 
Close-to-home farms with lots of vegetable and fruit trees, vines and herbs that give rural character have given way for massive structures with up to $100 \%$ coverage of hard surfaces thereby generating $100 \%$ run-off and heat, creates food shortage while traditional herbs go to extinction.

Uncontrolled massive building activities have moved beyond close-to-home farms to distant farms to claim farm-land and vegetation at different locations in respective watershed hence generating run off and causing deforestation and food shortage.

Factories and hauling activities, large volume of cars at weekends and festive periods pollute the environment with noise, fumes and droppings. Over-clearing of site and establishment of numerous access roads serving unplanned development open the land for erosion, and flooding which affect aquatic life through deposition in water bodies.

The continuous high rate of population growth puts a lot of pressure on the scarce land leading to more fragmentation of land and causes social vices.

Excessive farming causes soil bleaching while wrong technique of hillside farming causes landslide.

Underground water level is reduced drastically as more water is drawn through the borehole while little recharging goes on because pavements cover recharge areas.

Existing curricular on planning education did not address the peculiarity of rural growth in Nigeria hence the recycling of ignorance and ineffective regional planning policy.

Gross ignorance and insensitivity resulting from lack of knowledge of ecological consequences of unplanned building activities aggravated the issues.

Igbo rural landscape which represents one "Unique Native Resource” endowed with wealth of knowledge and comprising tropical vegetation, wildlife, aquatic life, human living system and cultural landmarks is being replaced aggressively with suburbanization and massive erosion to the detriment of future indigenes [9].
Absence of effective regional development control created the vacuum in which aggressive indiscriminate development thrived.

\section{Sustainable Intervention Plans}

A broad issue based 50-year regional cultural landscape master plan must be embarked upon with immediate, short and medium term intervention plans to be reviewed every five years. Public participation must be wholesome and involves the local residents and indigenes, physical planners, journalists, church organizations, town unions, traditional rulers, local government authorities, legislators, academic institutions, women organizations and NGOs (non-governmental organization) etc.

The elements of the sustainable regional master plan include but not limited to the following plans in the two aspects

\subsection{Education Plans}

Education plans are:

(1) Massive public enlightenment/education plan to sensitize the indigenes and other stake holders on the issues and the consequences. Journalists and churches must be part of the resource agents;

(2) Introduce from next year basic environmental studies in secondary education with emphases on environmental degradation so that the young ones will grow with the knowledge;

(3) The general studies programme in tertiary institutions must carry at least one semester course on environmental degradation and conservation and must be compulsory for all disciplines;

(4) Introduce environmental engineering programme to cover erosion, flooding, pollution and waste management;

(5) There must be short training programmes on environmental degradation and conservation for builders, engineers, farmers, civil servants etc.;

(6) Studies in rural landscape to be included in curricular for centre for environmental studies to be 
established in different institutions.

\subsection{Physical Development Plans}

Inter-state regional rural development plans to harmonize state plans particularly the areas in some watershed:

(1) Specify standards for coverage of pavements in aquifer and non aquifer recharge areas;

(2) Generate plans for rainwater harvesting and specify standards for run-off control for mandatory implementation;

(3) Generate standards and regulations for construction of rural roads;

(4) Produce forest regulation and regeneration plans to re-establish tropical plants and wildlife threatened to extinction [12];

(5) Develop soil restoration and conservation plans;

(6) Encourage and regenerate close-to-home farms with vegetable and fruit trees, herbs, spices, vines etc.;

(7) Develop effective techniques for intensive farming adaptable in the fragmented farm land to boost agricultural production in rural areas [11];

(8) Produce rural population growth reduction plans for effective control of population;

(9) Develop inter-state water resources development and protection plans;

(10) Set the standard for regional based erosion control master plan to be adopted by each state;

(11) Concept of extension planners. Each state government in the region to invest on training of landscape Architects and Town and Regional Planners with emphasis on Environmental Engineering to cover erosion and flood control, pollution and waste management, on-site and off-site run-off control etc.. The professionals will be employed and posted to local government headquarters from where they will be sent to communities as extension planners.

\section{Conclusions}

The resultant characteristic of the Igbo cultural region is a culmination of multiple impacts resulting from several incidences or events occurring over a period of time. Every event has a result that will have multiple impacts socially, economically, ecologically and physically or may generate sub events that also have multiply impacts.

A civilization with its wealth of knowledge established over a period of about 3,500 years is experiencing degradation accelerated in the last 30 years since the oil and trade boom. If the present pattern of development continues in the next 50 years a regional conurbation will emerge with complete destruction of convivial rural resources and consequently increased multiple impacts. Hence, the call for appropriate regional landscape intervention plans for the Igbo cultural landscape area which must be tackled through multi-dimensional approach with great sense of purpose.

\section{References}

[1] B.C. Ekweruo, Natural and cultural adaptations in Nigeria, Semester Project paper, Federal University of Agriculture, 1982.

[2] B.C. Ekweruo, Promotion of Education in Landscape Architecture, Nnamdi Press Tetlow Road, Owerri, 2000.

[3] B.C. Ekweruo, Adaptive Planning: A New Approach to Comprehensive Planning in a Developing Country, Focus on Nigeria, Project in Culturally Appropriate Design, 1984.

[4] R.K. Udo, Geographical Regions of Nigeria, Morrison and Gibb Ltd., London, 1981.

[5] C.S. Ola, Town and Country Planning Law in Nigeria, Oxford University Press, Ibadan, 1977.

[6] T. Shaw, Unearthing Igbo Ukwu-Archeological Discoveries in Eastern Nigeria, Oxford University Press, Ibadan, 1977.

[7] B.C. Ekweruo, Lessons from the Ibo traditional society, the art of living that sustained stable, enduring, recreational and dynamic society in a permanent region, in: The International Symposium on Harvesting and Sharing Indigenous Knowledge in Africa, Owerri, 2003.

[8] P.O. Nsugbe, Ohafia-A Matrilineal Ibo People, Clarendon Press, Oxford, England, 1974.

[9] B.C. Ekweruo, Urbanization pattern in Ibo and Yoruba region, Term Paper, Federal University of Agriculture, 1985. 
[10] B.C. Ekweruo, Traditional conservation methods as a way of life in Igbo Communities, in: The Conference on Harvesting Indigenous Knowledge by Whelan Research Academy for Religion, Culture and Society, Owerri, 2003, pp. 340-357.
[11] B.C. Ekweruo, Igbo regional landscape and traditional agriculture, in: Ideato South Seminar on Regional Development, Owerri, 2004.

[12] K.A. Longman, J. Jenike, Tropical Forest and Its Environment, Longman, London and New York, 1978. 